\title{
Ampliação de direitos políticos de sufrágio universal e voto direto no
}

\section{Brasil}

\author{
Expansion of political rights of universal suffrage and direct vote in Brazil
}

André Mendes da Fonseca Ferraz ${ }^{1}$

\section{Resumo}

\begin{abstract}
Este artigo tem por objetivo investigar a possibilidade de aplicação reflexiva do paradigma habermasiano da política deliberativa na prática democrática brasileira, visando uma ampliação ainda maior dos direitos humanos. Esse paradigma, tem como pressupostos: (a) o agir comunicativo; (b) a ampla participação política direta e individual de todos os concernidos nas decisões; (c) consenso normativo, que admite e se alimenta do dissenso como possibilidade de transceder ao factual; (d) circunscrição e não-circunscrição do mecanismo comunicativo; e (e) institucionalização do poder comunicativo pelo sufrágio universal e voto direto. Para tanto, analisa a necessidade de ampliação de garantias de consulta popular, considerando: o art. 81§1ำ da Constituição Federal de 1988 (CF/88), segundo o qual ocorrendo a vacância nos últimos dois anos do período presidencial, a eleição para os cargos de Presidente e Vice-Presidente da República será feita pelo Congresso Nacional, conflitando com a cláusula pétrea do art. 60 §4ㅇda CF/88; o art. 100 da $\mathrm{CF} / 88$ e sua flagrante violação pela lógica dos Decretos Presidenciais que vêm sendo utilizados para preterir pagamentos prolatados em decisões da Corte Interamericana de Direitos Humanos ignorando o procedimento e a fila dos precatórios; e o art. 49 inciso I da CF/88, que, na prática, tratados internacionais não convalidados pelo Congresso Nacional vêm sendo, muitas vezes, replicados pelo Presidente da República no ordenamento jurídico interno e, ainda reeditados, por Medida Provisória; e os Conselhos de Gestão, que perpetuam a lógica de dominação política do sistema representativo. Para essas possibilidades propõe-se proceder mediante plebiscito, na forma do inciso I do artigo 14 da Constituição Federal de 1988, e da Lei 9.709/98.
\end{abstract}

Palavras-chave: Democracia Procedimental, Política deliberativa, Sufrágio universal e voto direto, Constituição Federal de 1988.

\begin{abstract}
This article aims to investigate the possibility of applying reflective Habermasian paradigm of Deliberative Politics in democratic practice in Brazil, aiming at an even greater expansion of Human Rights. This paradigm has as its assumptions: (a) communicative action, (b) broad participation in the direct political and individual
\end{abstract}

1 André Mendes da Fonseca Ferraz, Mestrando em Sociologia e Direito pela Universidade Federal Fluminense - PPGSD/UFF, Email: andrefferraz0348@gmaill.com. 
decisions on all concerned, (c) normative consensus that accepts and feeds thedissension as a possibility to transcend the factual, (d) non-district and district communication mechanism, and (e) institutionalization of Communicative Power by universal suffrage and direct vote. It analyzes the need for expansion of guarantees of public consultation, taking into consideration: art. 81§10 of the Constitution of 1988 (CF/88), whereby the vacancy occurring in the last two years of presidential election to the offices of President and Vice-President of the Republic shall be made by Congress, conflicting with the entrenchment clause of Art. 60\$4ㅇ of CF/88; art. 100 of $C F / 88$ and its flagrant violation by the logic of presidential decrees that have been used to postpone decisions on payments certain of American Court of Human Rights ignoringthe procedure and the queue of the writ, and art.49 section I of $\mathrm{CF} / 88$, that in practice, international treaties do not validated by the National Congress have been often replicated by the President on domestic law and also reissued by Provisional Measure, and the Boards of Management, that perpetuate the logic of political domination of the representative system. To these possibilities is proposed to proceed by referendum, as provided in subsection I of Article 14 of the Constitution of 1988 and Law 9.709/98.

Keywords: Procedural Democracy; Deliberative Politics; Universal Suffrage and Direct Election; 1988 Federal Constitution.

\section{Introdução}

Diante da crise do Estado Social e de legitimidade do sistema político representativo, na qual a participação popular restringe-se ao momento eleitoral, representantes eleitos decidem arbitrariamente segundo interesses privados, ignorando as necessidades e a vontade dos eleitores, e o direito limita-se a um sistema de legalidade e coercitividade.

E, frente a insuficiência dos procedimentos de democracia participativa adotados pelos Conselhos de Gestão, nos quais, embora se objetive contrapor ao poder políticoeconômico a participação de pessoas jurídicas representantes de interesses da sociedade civil, a participação direta individual da população reduz-se a mera oitiva e, ao final, seus representantes decidem segundo imperativos sistêmicos. Ressalvando-se aqui, no entanto, os Orçamentos Participativos, que inovaram ao permitir o voto direto dos cidadãos.

Partilhando da concepção de direitos políticos como direitos humanos fundamentais, e inspirados pela proposta habermasiana de reconstrução de sistemas jurídicos e de uma ampliação ainda maior dos Direitos Humanos, alicerçada num sistema de cooperação de direitos subjetivos, concepção linguístico-pragmática de verdade, agir comunicativo, ética do discurso e na ideia de política deliberativa, viabilizada em última instância pelos direitos políticos de sufrágio universal e voto direto, examina-se neste artigo 
algumas possibilidades de aplicação reflexiva da proposta habermasiana na prática democrática brasileira, sob os trilhos de uma ampliação ainda maior dos direitos políticos de sufrágio universal e voto direto.

São elas, as posibilidades: art. 81 §1으 da Constituição Federal de 1988 (CF/88), segundo o qual ocorrendo a vacância nos últimos dois anos do período presidencial, a eleição para ambos os cargos de Presidente e Vice-Presidente da República será feita pelo Congresso Nacional, conflitando com a cláusula pétrea do §4ㅇ do art. 60 e art. 100 ambos da CF/88 e sua flagrante violação pela lógica dos Decretos Presidenciais que vem sendo utilizados para preterir pagamentos prolatados em decisões da Corte Interamericana de Direitos Humanos burlando o procedimento e a fila dos precatórios, bem como a competência do Poder Judiciário de garantir seu cumprimento pelo Poder Executivo; art. 49 inciso I da $\mathrm{CF} / 88$, no qual, na prática, tratados internacionais não convalidados pelo Congresso Nacional vem sendo, muitas vezes, replicados pelo Presidente da República no ordenamento jurídico interno e, ainda, reeditados por meio de Medida Provisória; e dos Conselhos de Gestão, que perpetuam a lógica de dominação política do sistema representativo.

\section{A proposta Habermasiana e sua perspectiva sobre Direitos Humanos}

Em "Direito e Democracia: entre facticidade e validade", no conceito de mundo da vida, formado por indivíduos, sociedade e cultura, e que sofre processo de colonização por vários mundos circundantes, Habermas (1997) discorda da Autopoesis de Luhmam, ao entender que linguagem e razão se interpenetram nesses mundos por meio da circulação comunicacional, validando não somente atos de fala como as formas de vida por ela reproduzidas, pelo reconhecimento intersubjetivo de pretensões de validade criticáveis. E ainda, atribuindo importância central ao direito na manutenção da comunicação e na mediação com os mundos do dinheiro e do poder administrativo, surdos à linguagem coloquial, como base de validade da integração social. Diante disso, sem renunciar a dupla função normativa e social integradora do direito, possibilitador dos processos de socialização e convivência, o autor propõe a reconstrução da Sociedade e do Estado de direito, alicerçado numa teoria da ação comunicativa, que substitui a razão prática pela razão comunicativa 
com a pretensão de verdade intersubjetiva da linguagem e na ideia de direitos subjetivos cooriginários de direitos objetivos, culminando assim com a proposta de ampliação dos direitos humanos a partir de um sistema de cooperação de direitos subjetivos e de autolegislação democrática, garantido por uma democracia procedimental e uma política deliberativa, capazes de conciliá-los com soberania popular, de forma a resgatar sua legitimidade social a partir de uma fundamentação lingüístico-discursiva para as normas e valores. Dessa forma, ele resgata o ideal Marxista de socialismo, de neutralização do poder social e racionalização de dominação política no seio da discussão pública, pela auto-organização democrática de uma comunidade jurídica emancipada, na qual cada indivíduo seja ao mesmo tempo, autor e destinatário de seu direito, bem como dos rumos de sua comunidade. (HABERMAS, 1997, p.12, 20, 25, 33-35, 47, 65, 72, 82, 111-112)

Para esse autor, direitos subjetivos são todos os direitos que sujeitos de uma comunidade jurídica se atribuem reciprocamente, definindo liberdades de ação iguais para todos, pelo entendimento de sujeitos que agem comunicativamente e cooperam entre si. (HABERMAS, 1997, p. 120-121)

E ainda, agir comunicativo é um fenômeno presente no munda da vida, em que a linguagem natural, a necessidade de comunicação e de entedenimento nessa comunicação geram um enfoque performativo, obrigando os indivíduos a sair do egocentrismo e se colocar sob os critérios públicos da racionalidade do entendimento, possibilitando integração social por intermédio da força de uma linguagem compartilhada intersubjetivamente. $\mathrm{O}$ alto risco de dissenso, alimentado a cada passo por experiências contingenciais repletas de surpresas, tornaria a integração social pelo uso da linguagem orientado pelo entendimento inteiramente implausível, se o agir comunicativo não estivesse embutido em contextos do mundo da vida os quais fornecem apoio por meio de um maciço pano de fundo consensual. E o que está embutido na base de validade da fala também se comunica às formas de vida reproduzidas pela via do agir comunicativo. (HABERMAS, 1997, p. 20, 45, 40).

A partir desses elementos presentes na comunicação cotidiana, o autor identifica as condições ideais de fala para um processo dialógico-discurso orientado ao entendimento mútuo entre sujeitos, em sua Ética do Discurso, em "Consciência Moral e Agir Comunicativo", no capítulo "Notas pragmáticas para a fundamentação de uma ética do discurso", que traduzem-se em competências atitudinais, na forma de regras do Discurso: 
(1) Pressupostos lógico-semântico: (1.1) A nenhum falante é lícito contradizer-se; (1.2) Todo falante que aplicar um predicado " $F$ " a um objeto "a" tem que estar disposto a aplicar " $F$ " a qualquer outro objeto que se assemelhe a "a" sob todos os aspectos relevantes. (2) Pressupostos pragmáticos: (2.1) A todo falante só é lícito afirmar aquilo em que ele próprio acredita; (2.2) Quem atacar um enunciado ou norma que não for objeto da discussão tem que indicar uma razão para isso. (3) Pressupostos retóricos do processo: (3.1) É lícito a qualquer sujeito capaz de falar e agir participar de Discursos; (3.2.a) É lícito a qualquer um introduzir qualquer asserção no Discurso; (3.2.b) É lícito a qualquer um introduzir qualquer asserção no Discurso; (3.2.c) É lícito a qualquer um manifestar atitudes, desejos e necessidades; e, (3.3) Não é lícito impedir falante algum, por uma coerção exercida dentro ou fora do Discurso, de valer-se de seus direitos estabelecidos em (3.1) e (3.2). (HABERMAS, 1989, p. 111-113)

Ocorre que muitas dessas condições ideais de fala encontram-se presentes no mundo da vida, encontram-se pressionados por imperativos sistêmicos e, na prática social, neutralizados pela incapacidade de institucionalização do seu decorrente arranjo comunicativo. Daí, o autor apresenta a idéia de Política Deliberativa, que caracteriza-se como direito de autorregulação de uma comunidade jurídica, e se fundamenta nos seguintes pressupostos: (1) deliberações inclusivas e públicas, princípio do amplo acesso a participação política ativa direta e individual nas decisões; (2) acesso e simetria informacional; (3) processos discursivos de argumentação calcados no agir comunicativo, segundo regras da ética do discurso; (4) consenso, que se alimenta do dissenso e renova a cada melhor argumento concepção linguístico-pragmática de verdade; (5) dissenso, enquanto faculdade racional de resgatar, a qualquer tempo, pretensões de validade criticáveis e de, encontrando melhor argumento, possiblitar à comunidade de intérptretes superar o factual; (6) institucionalização jurídica do poder comunicativo resultante do consenso, tanto da esfera pública formal como informal, e (7) as estratégias de superação do dissendo da circunscrição (Eingrezung) e da não-circunscrição ou liberação (Entschrãnkung) do mecanismo comunicativo, nas esferas políticas formal e informal, respectivamente. (HABERMAS, 1997, p. $58,164)$.

Ao pensar nas condições de efetividade à Política Deliberativa, o autor apresentanos a ideia de Democracia Procedimental, como aquela capaz de oferecer as condições pragmático-formais nas quais uma constituição possa garantir condições equitativas para a institucionalização jurídica do poder comunicativo resultante de uma esfera pública pluralista 
e desconcentrada de uma sociedade complexa altamente diferenciada, principalmente, pelos direitos políticos de sufrágio universal e voto direto (HABERMAS, 1997, p. 158, 325,353).

Nesse modelo, ganham relevância à ideia de esferas públicas ${ }^{2}$ descentralizadas e autônomas, constituem-se num canal de medição e normatividade entre a Sociedade Civil ${ }^{3}$ e o Estado, em que as associações livres, formam os pontos de entroncamento de uma rede comunicacional nascidas do entrelaçamento de esferas públicas autônomas, constituem-se numa nova forma de soberania comunicativa. (HABERMAS, 1997, p. 272-273)

Para o autor, a esfera pública tem a função de captar e tematizar os problemas da sociedade como um todo, a partir dos contextos comunicacionais das pessoas virtualmente atingidas pela pressão social exercida pelo sofrimento que se reflete no espelho das experiências pessoais de vida. A esfera pública retira seus impulsos da assimilação privada de problemas sociais que repercutem nas biografias particulares. Em sociedades complexas, a esfera pública forma uma estrutura intermediária que faz a mediação entre o sistema político, os setores privados do mundo da vida e os sistemas de ação especializados em termos de funções, numa rede supercomplexa: (1) que se ramifica espacialmente num numero de arenas internacionais, nacionais, regionais, comunais, e subculturais, que se sobrepõem umas às outras; (2) que se articula objetivamente de acordo com pontos de vista funcionais, temas, círculos políticos, e etc.; (3) que se diferencia por níveis, de acordo com a densidade da comunicação, da complexidade organizacional e do alcance; (4) constituídas pela linguagem comum ordinária; (5) constituídas de esferas públicas parciais e porosas, que permitem uma ligação e transcrição entre elas de modo contínuo, de forma (5.1) que se estendem radialmente em todas as direções, (5.2) que constituem uma ponte hermenêutica

2 O conceito habermasiano de esfera pública é um fenômeno social que pode ser descrito como espaço social (presença física) ou rede (presença virtual) de comunicação compartilhada intersubjetivamente (agir comunicativo) através de uma linguagem comum (estruturas comunicacionais) nas relações interpessoais (entre sujeitos iguais e livres orientados pelo entendimento em sua prática codidiana) que transcorrem num espaço público (físico ou virtual) do mundo da vida. (HABERMAS, 1997, p. 92-98, 107)

3 O conceito haberasiano de Sociedade Civil é o conjunto de movimentos associações, associações e organizações não estatais e não econômicas, que ancoram as estruturas de comunicação presentes da esfera pública nos componentes sociais do mundo da vida, captando ecos dos problemas sociais, que ressoam nas esferas privadas, condensam e institucionalizam os discursos capazes de solucionar os problemas, transformando-os em questões de interesse geral no quadro das esferas públicas, e os transmitem, a seguir para a esfera política. Esse processo discursivo reflete em suas formas de organização, abertas e igualitárias, cristalizam-se conferindo-Ihe continuidade e duração, formando um substrato organizatório do público de pessoas privadas que buscam interpretações públicas para suas experiências e interesses sociais, exercendo influência sobre a formação institucionalizada da opinião e da vontade. (HABERMAS, 1997, p. 99-100)

Revista de Direito PúBlico, Londrina, v. 7, N. 1, P. 125-148, JAN./ABR. 2012. 
entre um texto e outro; e (5.3) que suspendem qualquer regra de exclusão comunicacional (HABERMAS, 1997, p. 92-98, 107).

Nas esferas políticas, mesmo nas que formam mais ou menos absorvidas pelo poder, as relações de forças modificam-se tão logo a percepção de problemas sociais relevantes suscita uma consciência de crise na periferia. É se nesse momento, que os movimentos sociais se constituem, formulando um tema correspondente na esfera pública, e sua iniciativa podem ter sucesso nessa mobilização endógena da esfera pública. (HABERMAS, 1997, p. 116)

Nesse contexto, os movimentos sociais realizam uma dupla função política ${ }^{4}:$ (1) "através de uma ofensiva", tentam (1.1) lançar temas de relevância para toda a sociedade, (1.2) definir problemas, (1.3) trazer contribuições para a solução de problemas, (1.4) acrescentar bons argumentos e (1.5) denunciar argumentos ruins, a fim de (1.6) produzir uma atmosfera consensual capaz de (1.7) modificar os parâmetros legais de formação da vontade política e exercer pressão sobre os parlamentos, tribunais e governos em benefício de certas políticas; (2) "defensivamente", tentam (2.1) preservar estruturas da associação e da esfera pública, (2.2) produzir contra-esferas públicas subculturais e contra-instituições, (2.3) solidificar identidades coletivas e (2.4) ganhar novos espaços na forma de direitos mais amplos e instituições reformadas. (HABERMAS, 1997, p. 103, 114)

Assim, em Habermas, pela exigência de se ligar o sistema administrativo ao poder comunicativo, estatuidor de direitos e de mantê-lo longe das influências do poder social e da implementação fática de interesse privilegiados, contra a facticidade do poder não domesticado juridicamente, introduzida no Direito a partir de fora, tem-se a ideia de Estado de direito como mais uma instância normativa no âmbito da Sociedade, a partir de uma espiral da autoaplicação do direito, capaz de fazer valer a suposição internamente inevitável da autonomia política, num quadro garantido pelos direitos humanos e pelas esferas políticas subculturais que se sobrepõem umas às outras, cujas fronteiras reais, sociais e temporais são

4 Para o autor, esse modelo de iniciativa externa aplica-se à "situação na qual um grupo que se encontra fora da estrutura governamental: (1) articula uma demanda, (2) tenta propagar em outros grupos da população o interesse nessa questão, a fim de ganhar espaço na agenda pública, o que permite (3) uma pressão suficiente nos que têm poder de decisão, obrigando-os a inscrever a matéria na agenda formal, para que seja tratada seriamente. Esse modelo de formação de uma agenda pode predominar em sociedades mais igualitárias. Entretanto, o fato de ter adquirido o status de uma agenda formal não significa necessariamente que a decisão final das autoridades ou de que a atual política de implementação corresponderão às pretensões do grupo que formulara a demanda". (HABERMAS, 1997, p. 103, 114) 
fluidas e cujos fluxos comunicacionais, em princípio ilimitados, formam os componentes informais da esfera pública geral, na qual a integração social, que depende das condições de uma socialização instável, opera com suposições contrafactuais permanentemente ameaçadas. (HABERMAS, 1997, p. 61, 190; p. 32-33, 39)

\section{A crise do Estado Social}

Para Habermas (1987), em "A nova intransparência: a crise de bem-estar social e o esgotamento das energias utópicas", no projeto do Estado de Bem-Estar Social a utopia do trabalho heterônomo emancipado manteve sua importância central como referência à humanização do trabalho, ainda determinado de fora, mas apresentando-se sob condições reformadas, na meta do pleno emprego, renda mínima, e nas indenizações trabalhistas compensatórias dos riscos do trabalho assalariado:

\footnotetext{
O trabalho assalariado por tempo integral torna-se condição de possibilidade para que o cidadão alcance suas pretensões de direito enquanto cliente dos serviços de bem-estar social da burocracia estatal, e de compra enquanto consumidor de bens de massa. O Estado Social receberia sua legitimação política por meio de eleições gerais e alcançaria seus objetivos por meio de suas bases sociais, ou seja, pela legislação dos partidos dos trabalhadores e pelas negociações coletivas dos sindicatos autônomos. (HABERMAS, 1987, p. 107)
}

Para o autor, foi assim que as dimensões da felicidade e da emancipação confluíram com aquelas do incremento do poder e da produção de riqueza social, de forma que a razão instrumental desencadeada no interior das forças produtivas e a razão funcionalista desenvolvida nas capacidades de organizar e planejar deveriam preparar o caminho para vidas dignas do homem, igualitárias e, ao mesmo tempo, libertárias, pressupondo as formas subculturais de vida dos trabalhadores industriais como uma fonte de solidariedade, reforçada pelas relações de cooperação no interior da fábrica. (HABERMAS, 1987, p. 114)

Mas, o autor explica que tudo isso dependeria da capacidade do aparelho estatal intervir no sistema econômico capitalista, de forma a minorar as crises e a simultaneamente proteger a capacidade de concorrência das empresas no mercado internacional e de geração de emprego, possibilitando crescimento econômico e repartição de benefícios por redistribuição de 
renda, sem, com isso, desencorajar investimentos privados, e, ainda, regulando as condições de vida dos empregados:

Dessa forma, por meio do sistema de empregos e do poder estatal democraticamente legitimado, visava-se a parceria social e a pacificação dos conflitos de classe, internalizados em arenas das organizações sindicais aptas a negociações coletivas e nos partidos políticos, por meio da participação política dos trabalhadores aptos à normatização de direitos trabalhistas. Por outro lado, pressupondo a possibilidade de coexistência pacífica entre direito e democracia, visava-se moderar o processo natural de desenvolvimento capitalista pela mediação estatal por meio de intervenções na economia e regulações da vida social e privada. (HABERMAS, 1987, p. 107)

O autor ainda destaca que se acreditava que com o sistema de empregos e o poder estatal democraticamente legitimado, poder-se-ia alcançar a parceria social e a pacificação dos conflitos de classe, pela neutralização dos conflitos inerentes à classe trabalhadora assalariada, pela legislação dos partidos dos trabalhadores e pelas negociações coletivas dos sindicatos autônomos, numa ambiência de prosperidade material. Mas, que esses instrumentos se enfraqueceram, sobretudo, pela força decrescente de fatores como trabalho, produção e lucro na determinação da constituição e do desenvolvimento da sociedade em geral. (HABERMAS, 1987, p. 106-107)

Para ele, no limiar do século XXI, com empobrecimento estrutural dos países em desenvolvimento, o desemprego estrutural e os desequilíbrios sociais crescentes nos países desenvolvidos, numa ambiência de crises econômicas e de escassez de recursos materiais, e da atuação das organizações sindicais, partidos políticos, corporações legislativas e burocracias têm de levar em conta a pressão não declarada dos imperativos funcionais e colocá-los em harmonia com a opinião pública, resultou numa "política simbólica" e crescente desagregação no interior das classes trabalhadoras e das relações de cooperação e solidariedade no emprego. (HABERMAS, 1987, p. 104-105, 112-113)

Assim, o autor chega a concluir que:

Desde o princípio, o Estado nacional mostrou-se incapaz de assegurar adequadamente a política econômica keynesiana ante os imperativos do mercado mundial e das políticas de investimento multinacionais. Porém, é no âmbito interno que os limites do poder e da capacidade de intervenção do Estado estão mais evidentes, pois nesse ponto, o Estado social esbarra na resistência dos investidores privados à implementação de seus programas. (HABERMAS, 1987, p. 107) 
Para o autor, "o Estado social tem de deixar intacto o modo de funcionamento do sistema econômico", incapaz de exercer influência sobre a atividade privada de investimentos, senão por intervenções ajustadas ao sistema, pois não teve poder para isso, já que a redistribuição de renda limita-se, no essencial, a um relacionamento horizontal no grupo de trabalhadores dependentes e não toca na estrutura específica do poder de classe, especialmente na propriedade dos meios de produção. Além disso, as condições de valorização do capital são afetadas pelas políticas de Estado de bem-estar, sobretudo pela percepção subjetiva das empresas:

Os custos crescentes dos salários e dos encargos trabalhistas estimularam investimentos na racionalização da produção, o que, sob o signo da segunda revolução industrial intensificou a produtividade do trabalho e diminui o tempo do trabalho socialmente necessário, tornando a força de trabalho cada vez mais ociosa, apesar da tendência secular para a redução da jornada de trabalho. Além disso, com a falta de disposição para investimentos, a estagnação econômica, o desemprego crescente, e a crise do erário foram trazidos à percepção da opinião pública numa sugestiva ligação com os custos do Estado de bem-estar. (HABERMAS, 1987, p. 108)

Os reformadores consideraram ponto pacífico que o Estado ativo interviesse não apenas no ciclo econômico, mas também no ciclo vital de seus cidadãos, reformando as condições de vida dos empregados, afastando do mundo da vida dos trabalhadores dependentes os efeitos destrutivos de um crescimento econômico propenso à crise, sendo, com efeito, a meta do programa sócio-estatal. E dessa forma o Estado intervencionista teria alcançado, pela via parlamentar, a força e a capacidade para agir em relação à obstinação sistêmica da economia, realmente, alcançando, em certos casos, um alto grau de justiça. Mas, a esses instrumentos concatenou-se uma práxis de singularização dos fatos, normatização e vigilância, nas deformações de um mundo da vida regulamentado, analisado, controlado e protegido, com formas mais refinadas de exploração material e empobrecimento. (HABERMAS, 1987, p. 108)

Em suma, o projeto sócio-estatal como tal aloja uma contradição entre fins e meios. Seu objetivo é a criação de formas de vida estruturadas igualitariamente, gerando liberdade de movimentos para auto-realização e a espontaneidade individual. Mas obviamente esse objetivo não pode ser diretamente alcançado pela transição jurídico-administrativa de um programa político. A produção de novas formas de 
vida está além das forças de que o medium poder dispõe. (HABERMAS, 1987, p. 109)

E assim, chega a criticar o modelo do Estado social interventor e regulador, em sua crise de legitimidade:

Mas a administração não só estrutura o processo de legislação em grande parte ela também o controla. Ela tem de, por seu lado, selar compromissos com clientes poderosos. Também o governo tem de esforçar-se para obter simultaneamente apoio das massas e dos investidores privados. (HABERMAS, 1987, p. 109)

Para o autor, a crise decorre da própria inadequação dos paradigmas de uma sociedade de pleno emprego e legitimidade democrática, por um lado, e intervencionista e regulador estatal, por outro, e da matriz capitalista-moderna estar estruturada em torno deles:

Desde a metade dos anos 1970, os limites do projeto do Estado social ficaram evidentes, sem que até agora nenhuma alternativa clara seja reconhecível. Por um lado, os paradigmas do sistema de empregos e do poder estatal democraticamente legitimado e, por outro, os paradigmas intervencionista e regulador do Estado social, evidenciam-se como obstáculos que o Estado social pôs em seu próprio caminho, perdendo a capacidade de abrir possibilidades futuras de uma vida coletivamente melhor e menos ameaçada. [...] Fazem-se sentir as limitações estruturais sob as quais o compromisso sócio estatal foi criado e mantido. [...] É justamente a falta de alternativas, talvez mesmo a irreversibilidade dessas estruturas de compromisso, pelas quais se continua a lutar, que se apresenta o dilema de que o capitalismo desenvolvido nem pode viver sem o Estado social nem coexistir com sua expansão contínua. (HABERMAS, 1987, p. 106, 108-109)

O autor critica, ainda, o projeto da sociedade de trabalho, ao afirmar que "já não se trata de assegurar o emprego por tempo integral elevado à condição de norma", pois esse projeto não poderia se esgotar no estabelecimento de uma renda mínima, ainda que ignorando o potencial crescente e cada vez mais marginalizado daqueles que continuam na reserva, e os efeitos colaterais de uma proteção administrativa da existência como um todo, pois, quanto mais complexos se tornam os sistemas necessitados de controle, tanto maiores as possibilidades de efeitos colaterais disfuncionais. (HABERMAS, 1987, p. 112, 105) 
Com a mudança de paradigmas de sociedade do trabalho para a sociedade da comunicação $o^{5}$, cai o véu da dos projetos de uma totalidade concreta de possibilidades futuras de vida cuja totalidade possa ser emancipada, a partir de cima pelo Estado:

O conteúdo utópico da sociedade da comunicação se reduz aos aspectos formais de uma intersubjetividade intacta, e às condições necessárias, embora gerais, para uma práxis comunicativa cotidiana e para um processo de formação discursiva da vontade, as quais poderiam criar as condições para os próprios participantes realizarem segundo necessidades e ideias próprias, e por iniciativa própria as possibilidades concretas de uma vida melhor e menos ameaçada. (HABERMAS, 1987, p. 114)

\section{A crise de legitimidade do sistema político representativo e do direito coercitivo}

O Estado moderno pressupõe como princípio de sua própria verdade a soberania popular, e esta, por sua vez, deve ser a opinião pública, como origem de toda a autoridade das decisões totalitárias, de modo que falta à democracia a substância de sua própria verdade. O momento da "publicidade" que garanta a racionalidade deve ser salvo às custas de seu outro momento, o da generalidade, que garante a acessibilidade a todos. No processo de formação da opinião e da vontade nas democracias de massas, a opinião do povo, independente das organizações através das quais ela passa a ser mobilizada e integrada, raramente ainda mantem alguma função politicamente relevante. (HABERMAS, 2003, p. 276 - 277).

Em “Mudança estrutural da esfera pública”, Habermas (2003) demonstra que pouca coisa mudou da esfera pública helênica à esfera pública burguesa, enquanto espaço público destinado ao processo discursivo de formação da opinião e da vontade e, de decisão dos cidadãos sobre os rumos da pólis e de suas vidas, no que tange à meritocracia dos iguais, em que o acesso sempre dependeu de formação cultural e patrimônio. Demonstra ainda, que o conceito Kantiano original de esclarecimento racional dialético, traduzido como opinião pública crítica, geradora de um consenso, pela positivação no direito, continua válido como ideia norteadora nas democracias modernas. Mas, deixa a incógnita de como fazê-la aflorar diante de um Parlamento plebiscitário de decisões arbitrárias e discussões meramente encenadas, de uma publicidade midiática manipulativa e de uma opinião pública não crítica, com as quais a participação popular restringe-se ao momento eleitoral. Recorda-se a crítica de Marx, naquele contexto de ascensão ao Parlamento de uma classe burguesa que

\footnotetext{
5 Habermas, chega a falar em uma utopia de uma sociedade do trabalho. Para ele, esse pressuposto ou condição marginal do trabalho, nos dias de hoje, deslocou-se para o da comunicação.
} 
explorava a classe operária, o ideal da esfera pública burguesa como mera ideologia, a opinião pública como falsa consciência e o poder político como poder organizado de outras classes para sua dominação no sistema capitalista. Visando a neutralização do poder social e da dominação política, propôs um antimodelo pautado na emancipação da esfera pública cuja autonomia não deveria se basear mais na propriedade privada, mas que estivesse fundamentada na própria esfera pública, universalizada. (HABERMAS, 2003, p.16-17, 104, 154)

Em “O Poder Simbólico”, Bourdieu(1989) critica o empirismo moral de Kant a Hegel, em que cada indivíduo tem sua formação moral, tentando estabelecer normas morais de conduta, e essa moral vai nortear a interpretação da norma pelo indivíduo, como nos imperativos categóricos. Busca em Durkheim o entendimento do fenômeno de imigração das ideias, por meio do qual a transferência de ideias e seu simbolismo por grupos sociais costuma ocorrer de forma social arbitrária e autônoma, geralmente prejudicada pelo afastamento da própria concepção do sistema de referências teóricas nas quais se originaram, como instrumento de uma racionalidade para interpretação, com risco de reducionismo. (BOURDIEU, 1989, p. 7, §2으 e 8, §1으 e §2으)

A solidariedade, do antigo simbolismo cristão, passa a ser percebida como função social de um simbolismo estruturante e, mais tarde, por sua função política de um simbolismo estruturado, por se instituir no sistema estruturado de Estado, contribuindo assim para reprodução da ordem social. Esse poder estruturado, enquanto compreensão da lógica desse poder simbólico, passa a exigir a integridade como condição de integração moral, que gera presunção de legitimidade no mundo social. E nessa percepção das estruturas simbólicas como instrumento de dominação, se insere a língua como sistema simbólico estruturado de intelegibilidade, estrutura lógica, funções políticas (Marx), expressão sistemática no direito (Engels), relacionando-as com interesses de classes dominantes, que sob a visão de domínio, se afastam da visão de Durkehim de consenso. Assim, ocorre a instituição de linguagem e cultura de classe que consegue manipular a força estruturadora da linguagem simbólica para gerar um consenso e aceitabilidade integradoras entre as classes. (BOURDIEU, 1989, p.10)

Em "A nova intransparência: a crise de bem-estar social e o esgotamento das energias utópicas", Habermas (1987) critica o sistema representativo pelo fato dos partidos, corporações legislativas, burocracias terem de levar em conta a pressão não declarada dos 
imperativos funcionais e colocá-los em harmonia com a opinião pública, a fim de simultaneamente obter apoio das massas e dos investidores privados, o que resulta numa política simbólica. (HABERMAS, 1987, p. 113)

Em "Direito e Democracia: entre facticidade e validade", Habermas (1997) retoma essa discussão sob o questionamento da legitimidade de um sistema jurídico que se tornou mais um sistema de dominação, em que os representantes eleitos decidem arbitrariamente segundo interesses privados, pressionados por imperativos sistêmicos do mundo da vida, sobretudo pela mão invisível do mercado e cuja validação tem sido dada pela legalidade da forma jurídica e da coercitividade de suas sanções. Ele demonstra a crise de legitimidade do sistema político representativo, e da força normativa do direito racional, traduzidos na tensão entre facticidade do cumprimento de normas e sua aceitabilidade racional por todos os membros de uma dada comunidade jurídica. (HABERMAS, 1997, p. 54-62, 65, 121-122)

Nesse sentido, em "O futuro da democracia", Bobbio (2006) identifica as promessas da democracia indireta ou representativa: (a) da vontade geral como centro de poder e; (b) do representante cujo dever seria buscar apenas o bem comum; criticando (c) a dominação das oligarquias políticas; (d) o espaço limitado da participação popular; (e) a persistência de um poder invisível; e (f) a apatia política do cidadão. (BOBBIO, 2006, p. 34-35)

\section{A insuficiência dos procedimentos de democracia participativa adotados pelos Conselhos de Gestão, introduzidos no Brasil nas últimas décadas}

No Brasil, a partir da Constituição de 1988 os Conselhos Gestores surgem no âmbito das políticas públicas com o objetivo de exercer o controle social sobre o governo, a condução do repasse de recursos dos fundos federais, e do processo de descentralização, para atender aos interesses sociais ${ }^{6}$. (GOMES, 2003, p. 4, 15)

Ligados à gestão dos fundos nacionais de educação (Conselhos de Acompanhamento e Controle Social do Fundeb, Lei n. 0 11.494/07 e Conselho Nacional de Educação, Lei n.o 9.394/96); saúde (Lei n.o 8.142/90 Conselhos municipais de Saúde no âmbito do Sistema Único de Saúde - SUS); moradia (Conselho Nacional das Cidades); lazer (Conselho Nacional de Esportes, Decreto n. $94.201 / 2002$, e Conselho Nacional de Política

\footnotetext{
6 A exemplo dos artigos 5ㅇ, 6ㅇ, 10 e 225, todos da CF/88.
} 
Cultural, Decreto n. 5.520/05); proteção à maternidade e à infância (Conselho Nacional da Criança e Adolescente, Lei n. 8.742/93), e trabalho (Conselho Nacional do trabalho, Decreto n.o 5.063/04), rapidamente esses Conselhos se disseminam pelos demais entes da federação, seguindo os moldes do Governo Federal.

Constituindo normalmente órgãos públicos de composição paritária, distribuída entre sociedade civil e governo, criados por lei, de caráter obrigatório vinculado ao repasse de recursos federais, com atribuições consultivas, deliberativas e/ou de controle, os conselhos atuam em diversas frentes, como na gestão de políticas setoriais. (TEIXEIRA, 2000, p.102).

Seu desenho funcional objetiva contrapor ao poder político-econômico a participação de pessoas jurídicas representantes de interesses da sociedade civil, de forma que a participação direta e individual da população reduz-se a mera oitiva e, ao final, os Conselheiros também decidem desvinculada e arbitrariamente segundo interesses próprios. (GOMES, 2003, p. 42-50)

Dessa forma, esse modelo evidencia-se insuficiente na garantia legítima do interesse popular, tanto como órgão paritário, quanto como combinação de procedimentos de deliberação e representação, que perpetua a lógica de dominação política do sistema representativo.

Como solução, é preciso modificar sua estrutura funcional, garantindo os direitos políticos de sufrágio universal e voto direto, aos Conselhos de Gestão, na forma dos incisos I e II do artigo 14 da Constituição Federal de 1988, e da Lei 9.709/98.

A experiência de Orçamento Participativo no Brasil surgiu na cidade de Porto Alegre, em 1989. O Orçamento Participativo é um instrumento de participação popular nas discussões e definições sobre o orçamento público, municipal, regional ou federal. (FIGUEIREDO, 2010)

Atualmente, existem diferentes modelos de Orçamento Participativo sendo experimentados por diversos municípios em todo o Brasil. Mas, o problema de todos eles, enquanto modo presencial de votação que vem sendo adotado, reside de utilizarem-se da representatividade como meio de viabilização das decisões. O que, obviamente aproxima aos horrores do sistema político representativo. 
A solução seria a uniformização deles segundo o modelo de Orçamento Participativo Digital de Belo Horizonte, que inovou ao permitir o voto direto de todos os cidadãos, mostrando-se legítimo instrumento de autolegislação democrática, segundo a proposta habermasiana de sufrágio universal e voto direto. (FIGUEIREDO, 2010)

\section{Analisando as Possibilidades}

Um dos maiores absurdos da Constituição Federal de 1988, que incorporou a “Declaração Universal dos Direitos do Homem de 1948”, inaugurando, na prática, o voto direto e o sufrágio universal, é que ainda se tenham procedimentos como o do artigo $81 \S 1$ 을 da $\mathrm{CF} / 88$, in verbis:

Art. 81. Vagando os cargos de Presidente e Vice-Presidente da República, far-se-á a eleição noventa dias, depois de aberta a última vaga. §1ㅇ. Ocorrendo a vacância nos últimos dois anos do período presidencial, a eleição para ambos os cargos será feita trinta dias depois da última vaga, pelo Congresso Nacional, na forma da lei. (BRASIL, CF/88)

Segundo ele, ocorrendo a vacância nos últimos dois anos do período presidencial, a eleição para ambos os cargos será feita 30 dias depois da última vaga, pelo Congresso Nacional. Esse foi um dos artigos recepcionados pela Constituição Federal de 1988 das constituições dos regimes ditatoriais do Brasil.

Esse artigo está em conflito com o §4워 do art. 60, cláusula pétrea que tutela, dentre outros, o direito político de sufrágio universal e voto direto, in verbis:

Art. 60 [...] §4ㅇNão será objeto de deliberação a proposta de emenda constitucinal tendente a abolir: I - a forma federativa de Estado; II - voto direto, secreto, universal e periódico; III - a separação dos poderes; IV - os direitos e garantias individuais. (BRASIL, CF/88)

A solução vislumbrada é flexibilizar o cumprimento do art. 81 , §1으 da CF/88, de forma que o Congresso Nacional coordene realização de um plebiscito, na forma do inciso I do artigo 14 da Constituição Federal de 1988 e da Lei 9.709/98, para que a população decida individual e diretamente. Essa não é a única forma de autoritarismo presente na Constituição Federal, cujos demais exemplos serão abordados a seguir. 
Os tratados internacionais são homologados pelo Congresso Nacional, conforme inciso I do art. 49 da CF/88, com força de lei ordinária. Os tratados internacionais que versem sobre Direitos Humanos e forem homologados conforme §3ㅇ da CF/88, terão força de Emenda Constitucional, configurando-se parâmetro de controle das normas infraconstitucionais.

Em 1992, o Brasil ratificou a "Convenção Americana sobre Direitos Humanos", por meio do Decreto n. 678/92, conhecida como o Pacto de São José da Costa Rica, com força de Emenda Constitucional. Em 1998, houve o reconhecimento da jurisdição da Corte Interamericana, órgão previsto naquela convenção com competência para julgar os Estados-partes por violações de direitos humanos.

A Comissão Interamericana de Direitos Humanos é um órgão também criado pelo Pacto, com competência para examinar as denúncias encaminhadas por indivíduos ou entidades nãogovernamentais, contendo violação de direitos humanos por um Estado-parte do Pacto de São José da Costa Rica.

As sentenças da Corte Interamericana são equiparadas à sentença nacional, pois nesse tratadado assinado e ratificado pelo Decreto n. 678/92, transferiu parcela do seu poder de imperium quando se sujeitou à jurisdição da Corte, não havendo portanto, a possibilidade de se falar em desrespeito à autonomia ou em exclusividade do Poder Judiciário ao acatar tal decisão, sem a exigência de homologação, que se dá em casos como da sentença estrangeira, conforme letra "i" do inciso I do art. 105 da CF/88.

A partir de então, com a vigência do Tratado de São José da Costa Rica, por força do art. 46.a, transitando em julgado a sentença no ordenamento jurídico interno, que ofenda qualquer termo do Pacto, cabe recurso à Corte Interamericana de Direitos Humanos.

O art. 68.2 da Convenção Americana de Direitos Humanos dispõe que a indenização fixada na sentença da Corte poderá ser executada no país respectivo pelo processo interno vigente para a execução de sentenças contra o Estado. Nesse sentido, pode-se afirmar que as decisões da Corte Interamericana não necessitam de homologação na ordem interna, e que o procedimento a ser adotado para o pagamento das indenizações fixadas pela Corte Interamericana deve ser o mesmo adotado no ordenamento interno brasileiro, in casu, o procedimento especial do precatório. 
O precatório é um procedimento especial de execução por quantia certa contra a Fazenda Pública, regulado pelo art. 100 da CF/88 e arts. 730 e 731 CPC, que consiste na requisição da autoridade judiciária à autoridade administrativa, para que a verba necessária à satisfação do exequente seja incluída no orçamento do exercício financeiro subsequente e o respectivo crédito fique à disposição do requisitante. (JÚNIOR, 2005, p.46,50)

O precatório, segundo o $\S 10$ do art. 100 da CF/88, depende da existência de título

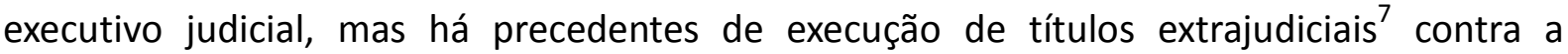
Fazenda Pública, em inúmeras decisões do STJ.

O precatório aplica-se a todas as execuções judiciais de créditos pecuniários, independente da natureza do crédito ou de quem figure como exequente, ressalvados os créditos de pequeno valor. (CUNHA, 2010, p.18, 21; JÚNIOR, 2005, p.58-59)

Para a Justiça Federal o valor teto dispensado de precatório é de 60 salários mínimos, fixado pela Lei 10.259/2001. O §3ㅇ do art. 100 CF/88 (Emenda Constitucional - E.C. n.ㅇ 30) estende a dispensa de precatório à União, Estados e Municípios. Embora autorizados no §5ㅇ do art. 100 CF/88 a adotar limites próprios, enquanto não estabelecerem em lei própria tal limite prevalece, transitoriamente, por força do art. 87 da ADCT (E.C. n.o 37), o limite de 40 salários mínimos perante a Fazenda dos Estados e do Distrito Federal, e de 30 salários mínimos perante a Fazenda dos Municípios.

O sistema de precatórios surgiu com a Constituição de 1934 no intuito de moralizar os pagamentos feitos sem critério pelo Estado. Até então, o sistema utilizado de pagamento das sentenças judiciais condenatórias ao erário era de submissão "aleatória", o que estimulava a advocaia administrativa e favorecia o pagamento de certos créditos em relação a outros. (PETIOK, 2005, p. 130-131).

Com a promulgação da CF/88, haviam duas filas em ordem cronológica de precatório, sendo uma para créditos de natureza alimentícia e outra para os de natureza não alimentar, sendo que estes últimos eram pagos prioritariamente em relação aos primeiros. (CUNHA, 2010. p. 19)

7 STJ, 2a T., Resp. 289.421-SP, Rel. Min. Eliana Calmon, ac. 5.3.2002; no mesmo sentido: STJ, 3a T., Resp 42.7746/SP, Rel. Min. Costa Leite, ac. 9.8.1994; RSTJ 63/435; STJ, 3a T., Resp 79.222/RS, Min. Rel. Nilson Novaes, ac. 25.11.1996, RSTJ 95/259. 
Com a Emenda Constitucional n. 62/2009, que alterou a redação do art. 100 CF/88, passaram a existir três ordens cronológicas distintas elencadas conforme prioridade no pagamento $^{8}:$ (1) a primeira, relativa aos débitos de natureza alimentícia cujos titulares tenham 60 anos de idade ou mais na data de expedição do precatório ou sejam portadores de doença grave ${ }^{9}$, até o valor equivalente ao triplo do valor dispensado de precatório; (2) a segunda, relativa aos demais débitos de natureza alimentar e a terceira, relativa aos demais débitos de outra natureza.

Os débitos de natureza alimentícia compreendem todos aqueles decorrentes de salários, vencimentos, proventos, pensões e suas complementações, benefícios previdenciários e indenizações por morte ou invalidez, fundadas na responsabilidade civil, em virtude de sentença transitada em julgado. (BRASIL, §1ㅇA do art. 100 da CF/88, introduzido pela E.C. n.o 30/2000)

Embora não seja entendimento pacífico, há doutrinadores que entendem tratar-se de rol meramente exemplificativo ${ }^{10}$. Esse entedimento tornaria possível as indenizações fixadas pela Corte Interamericana de Direitos Humanos, serem consideradas como créditos de natureza alimentícia, nos termos do art. 100 da CF/88.

Ocorreu que em 22 de novembro de 1999, a brasileira Irene Ximenes Lopes exerceu seu direito de petição perante a Comissão Interamericana de direitos Humanos, levando ao seu conhecimento divesas atrocidades cometidas a seu irmão Damião Ximenes Lopes, que culminaram com a sua morte em uma clínica psiquiátrica em Sobral - CE, alegando culpa do Estado Brasileiro, uma vez que a referida clínica era conveniada ao Sistema Único de Saúde SUS, ou seja, prestava serviço público e alegou, ainda, a demora na prestação jurisdicional e omissão na conduta de investigação dos fatos. Após a análise do caso Daniel Ximenes Lopes, caso n. 12.237, a Comissão Interamericana o apresentou para julgamento pela Corte em outubro de 2002. Verificou-se que Damião fora vítima de tortura e, ainda, a lentidão da Justiça Brasileira no despacho dos processos civil e criminal, que após sete anos do ocorrido, ainda não haviam sido concluídos. Assim, em 2006, condenou o Brasil por violação dos direitos humanos nos artigos 4으 (direito à vida), 5으 (direito à integridade pessoal), 8o (direito às

Conforme $\S 2^{\circ}$ do art. $100 \mathrm{CF} / 88$, Súmula 655 do STF, e Súmula 144 do STJ.

9 Cunha (2010) defende a necessidade de definição legal de doença grave, e de regulamentação dessa prioridade. (CUNHA, 2010, p.21)

10 STF, 2a.T., em sede de RE 170.220-6/SP, Rel. Min. Marco Aurélio, ac. 19.5.1998, DJU 7.8.1998. 
garantias processuais), e 25 (direito à proteção judicial) todos do Pacto de são José da Costa Rica. Essa sentença impôs ao Brasil a obrigação de pagar uma indenização pecuniária aos familiares da vítima, além de medidas de não repetição, na forma de políticas públicas de capacitação profissional para os profissionais de atendimento psiquiátrico do SUS.

Em relação às políticas públicas de medida de não repetição, algumas foram adotadas e reconhecidas na própria sentença, como a aprovação da Lei n.10.216/01, a Lei da Reforma Psiquiátrica. Em relação à indenização pecuniária, o governo brasileiro editou o Decreto n.으 6.185/07 autorizando a Secretaria Especial de Direitos Humanos, da Presidência da República, a dar cumprimento à sentença, considerando a criação prévia de uma rubrica orçamentária para pagamento de indenização a vítmas de violações de obrigações contraídas pela União por meio de adesão a tratados internacionais de proteção aos direitos humanos ${ }^{11}$.

Formalmente, ao ratificar o Pacto de São José da Costa Rica, o Brasil assumiu o dever de adequar seu ordenamento jurídico interno à norma internacional ${ }^{12}$, não podendo invocar questões de ordem interna para descumprimento de uma Corte Internacional ${ }^{13}$. Mas, ao proceder dessa forma, de cumprimento mediante decreto, o Presidente da República burla o procedimento e a fila dos precatórios, bem como a competência do Poder Judiciário de garantir seu cumprimento pelo Poder Executivo. Trata-se portanto de flagrante violação do art. 100 da CF/88, gerando incertezas e insegurança jurídica no ordenamento jurídico interno.

Como não houve um posicionamento do Congresso Nacional sobre a forma de excecução dessas decisões no ordenamento jurídico interno ou controle concentrado abstrato de constitucionalidade por parte dos legitimados ${ }^{14}$, e muito menos o controle difuso concreto daqueles preteridos que se encontram nas filas tradicionais do precatório ${ }^{15}$, na atual situação, é latente a necessidade de uma Emenda Constitucional disciplinando o procedimento.

A questão é se realmente há interesse do povo que o Congresso Nacional elabore uma Emenda Constitucional para preterir pagamentos prolatados em decisões da Corte Interamericana de Direitos Humanos, seguindo a lógica dos Decretos Presidenciais. Nesse

1 Conforme art. 10 do Decreto n.o 6.185/07.

Conforme art. 2 o do Pacto de São José da Costa Rica.

Conforme art. 27 da Convenção de Viena.

14 Conforme art. 103 inciso I CF/88, sobre competência originaria para ADIN direta e indireta.

15 Conforme princípio da preterição. 
sentido, melhor seria a realização de um plebiscito, na forma do inciso I do artigo 14 da Constituição Federal de 1988, e da Lei 9.709/98, verificando o interesse da população sobre o assunto.

Outro exemplo, é o do inciso I do art. 49 da CF/88, in verbis:

É competência exclusiva do Congresso Nacional: I - resolver definitivamente sobre tratados, acordos ou atos internacionais, que acarretam encargos ou compromissos gravosos ao patrimônio nacional. (BRASIL, CF/88)

Com a redação dada ao art. 62 pela E.C. 32/2001, o Presidente da República pode reeditar uma Medida Provisória a cada sessão legislativo, ou seja, a cada ano, in verbis:

Art. 62. em caso de relevante urgência, o Presidente da República poderá adotar medidas provisórias, com força de lei, devendo submetê-las de imediato ao Congresso Nacional. [...] §7ํㅡ prorroga-se uma única vez, por igual período, a vigência da medida provisória, no prazo de 60 dias, contado da sua publicação, não tiver sua votação encerrada, nas duas casas do Congresso Nacional. [...] §10․ Vedada a reedição, na mesma sessão legislativa, de medida provisória que tenha sido rejeitada ou que tenha perdido a sua eficácia por decurso de prazo. (BRASIL, $\mathrm{CF} / 88$ )

O problema é que, na prática, existem tratados internacionais não convalidados pelo Congresso Nacional na forma do inciso I do art. 49 da CF/88, e o Presidente da República, muitas vezes, replica o teor desse tratado no ordenamento jurídico interno e, ainda, fica reeditando-o por meio de Medida Provisória.

Como exemplo, tem-se a Medida Provisória de n.ㅇ 2.200/2001, lei que institui o ICPBrasil, Sistema Integrado de Chaves Públicas e Privadas, lei modelo da UNCITRAL/ONU, que não foi aprovada pelo poder constituinte derivado na forma do inciso I do artigo 49 CF/88, mas vem sendo reeditado pelo Presidente da República, várias leis do ordenamento jurídico interno, como a lei do processo eletrônico da justiça federal e a lei que permite ao Presidente sancionar leis por via eletrônica, baseiam-se no ICP-Brasil.

Nessa questão, a solução seria a realização de um plebiscito, na forma do inciso I do artigo 14 da Constituição Federal de 1988, e da Lei 9.709/98, verificando o interesse da população de aceitar ou não essas leis do poder constituinte transnacional. 


\section{Conclusão}

Reavaliar as estruturas do Estado Democrático de Direito e propor a sua reconstrução de forma intersubjetiva significa a busca por um espaço plural de participação feita com deliberação, respeito, tolerância e reconhecimento das minorias, ambiência de consenso e dissenso, argumentação e diálogo, solidariedade e inclusão, e, principalmente, de luta pela dignidade humana.

Com efeito, a teoria habermasiana supera alguns pontos da democracia participativa: além da inclusão do povo nas etapas decisórias, propõe uma relação argumentativa crítica entre os cidadãos, que além da reflexividade educativa, passam a ser capazes de originar opiniões livres e racionais que expressem mais adequadamente a vontade coletiva no seio da discussão pública, bem como de auto-organização democrática, em que cada indivíduo seja, ao mesmo tempo, autor e destinatário de seu direito, bem como dos rumos de sua comunidade jurídica emancipada.

Assim, para a aproximação da realidade democrática brasileira, cuja Constituição permanece assombrada por resquícios autoritários e práticas intransparentes, a proposta habermasiana de uma democracia procedimental calcada na política deliberativa, os direitos políticos de sufrágio universal e voto direto ganham importância central à institucionalização jurídica da opinião e da vontade de uma esfera pública pluralista e desconcentrada de uma sociedade complexa altamente diferenciada.

Nesse sentido, evidencia-se como fundamental, no Brasil, a ampliação de garantias constitucionais de consulta popular, quando das possibilidades previtas nos artigos $81 \S 1$, 100 e 49 inciso I da Constituição Federal de 1988, e aos Conselhos de Gestão as quais se propõe proceder mediante plebiscito, na forma do inciso I do artigo 14 da Constituição Federal de 1988, e da Lei 9.709/98.

\section{Referências}

BRASIL. Constituição Federal de 1988. Disponível em: <http://www.planalto.gov.br/ccivil_03/constituicao/ConstituicaoCompilado.htm>. Acesso em: 05 abr. 2011. 
. Lei n. 9.709/98, que regulamenta os procedimento de consulta popular do artigo 14 da Constituição Federal de 1988. Disponível em:

https://www.planalto.gov.br/ccivil_03/leis//9709.htm. Acesso em 05 abr. 2011.

. Convenção Americana sobre Direitos Humanos Pacto de São José da Costa Rica. Disponível em: <http://www.planalto.gov.br/ccivil_03/decreto/1990-1994/anexo/and67892.pdf>. Acesso em: 05 abr. 2011.

BOURDIEU, Pierre. O Poder simbólico. Rio de Janeiro: Editora Bertrand Brasil, 1989.

BOBBIO, Norberto. O futuro da democracia . Trad. por Marco Aurélio Nogueira. 10. ed. SP: Paz e Terra, 2006.

CUNHA, Leonardo José Carneiro da. Revista Dialética do Direito Processual: A execução contra a fazenda pública e as alterações impostas pela Emenda Constitucional n. 0 62/2009. 85.ed. SP: 2010. p. 19-37.

FIGUEIREDO, Frederico de Carvalho. Da administração pública gerencial ao orçamento participativo digital - buscando a participação popular. Disponível em: <www.eumed.net/rev/cccss/05/fmok.htm>. Acesso em: 05 nov. 2010.

GOMES, Eduardo Granha Magalhães. Conselhos Gestores de Políticas Públicas: Democracia, Controle Social e Instituições. São Paulo: EAESP/FGV, 2003.

HABERMAS, Jürgen. A nova intransparência: a crise de bem-estar social e o esgotamento das energias utópicas. Trad. Carlos Alberto Novaes. Revista Novos Estudos, n. 18. CEBRAP, 1987.

. Direito e Democracia: entre facticidade e validade. Rio de Janeiro: Tempo Brasileiro, 1997. v. 1.

. Direito e Democracia: entre facticidade e validade. Rio de Janeiro: Tempo Brasileiro, 1997. v. 2.

. Mudança estrutural da esfera pública: investigações quanto a uma categoria da sociedade burguesa. Traduzido por: Flávio R. Kothe. Rio de Janeiro: Tempo Brasileiro, 2003.

. Notas pragmáticas para a fundamentação de uma ética do discurso.

Consciência moral e agir comunicativo. Trad. Guido A. de Almeida. Rio de Janeiro: Tempo Brasileiro, 1989. Cap. 3.

THEODORO JÚNIOR, Humberto. A execução contra a fazenda pública e os crônicos problemas do precatório. Belo Horizonte: Editora Del Rey, 2005. p. 45-66. 
MENDES; Gilmar Ferreira. Caderno de Direito Constitucional: Evolução do Direito Constitucional Brasileiro e Controle de Constitucionalidade. v. 5. Escola de Magistratura do Tribunal Regional Federal da 4a Região - EMAGIS, 2006.

TEIXEIRA, Elenaldo Celso. Conselhos de Políticas Públicas. São Paulo: Pólis, 2000. 